Challenges and weaknesses in the use of concept maps as a learning strategy in undergraduate health programs

Enios Carlos Duarte
Centro Universitário Adventista de São Paulo - UNASP, SP, Brazil
Ana Claudia Loureiro
Universidade Virtual do Estado de São Paulo - UNIVESP, SP, Brazil
Cristina Zukowsky-Tavares
Centro Universitário Adventista de São Paulo - UNASP, SP, Brazil

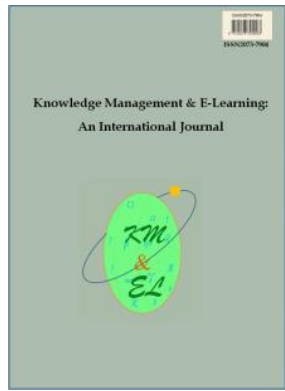

Knowledge Management \& E-Learning: An International Journal (KM\&EL) ISSN 2073-7904

Recommended citation:

Duarte, E. C., Loureiro, A. C., \& Zukowsky-Tavares, C. (2017). Challenges and weaknesses in the use of concept maps as a learning strategy in undergraduate health programs. Knowledge Management \& ELearning, 9(3), 380-391. 


\title{
Challenges and weaknesses in the use of concept maps as a learning strategy in undergraduate health programs
}

\section{Enios Carlos Duarte}

Centro Universitário Adventista de São Paulo - UNASP, SP, Brazil

E-mail: enios.duarte@unasp.edu.br

\author{
Ana Claudia Loureiro* \\ Universidade Virtual do Estado de São Paulo - UNIVESP, SP, Brazil \\ E-mail: aloureiro@usp.br
}

\section{Cristina Zukowsky-Tavares}

Centro Universitário Adventista de São Paulo - UNASP, SP, Brazil

E-mail: cristina.tavares@unasp.edu.br

*Corresponding author

\begin{abstract}
This paper considers the analysis of concept maps utilized as a learning tool in disciplines dealing with immunological responses in two undergraduate Health programs. In total, 48 concept maps were assessed regarding their propositions and structure. The clarity of the propositions was analyzed by using the Propositional Clarity Table and they were classified as adequate propositions (AP) and inadequate propositions (IP). In 48 concept maps, 648 propositions were analyzed in order to determine semantic clarity and conceptual mistakes. Assessments revealed that $69 \%$ of the propositions were classified as adequate and $31 \%$ as inadequate. All the maps analyzed were categorized as showing a network structure. However, when correlating the connections established among the several types of response by the immune system, it was found that despite being structured as a network, only $31.2 \%$ of the concept maps indicated conceptual relationships between the modes of immune response. $27 \%$ of the concept maps were made with a high rate of proficiency. Upon the results of our analysis, we realized that there is still a long way in developing the mapping strategy. For us, this low percentage is related to the way undergraduates assimilate the mapping processes. This is a challenge which also reveals limits and weaknesses that may be addressed in future studies. It was noted that results bring into focus that the undergraduates' learning of concepts associated with the bases of the immunological responses occurred in a meaningful way.
\end{abstract}

Keywords: Meaningful learning; Meaning construction; Concept maps; Health teaching

Biographical notes: Enios Carlos Duarte has a M.Sc. in Science from the University of São Paulo and graduated in Biological Science. He works as assistant professor in undergraduate programs of Biological Science, Nursing, Physical Therapy, and Nutrition at the Centro Universitário Adventista of São Paulo. His research interests include teaching and learning Science and Biology and the Teacher Education in Science and Biology. 
Ana Claudia Loureiro has a PhD in Education from the School of Education at USP. She works as a supervisor in Methodology and Distance Education for UNIVESP, and has been guest professor of CEDESS - Center for the Development of Higher Education in Health of UNIFESP - Federal University of São Paulo.

Cristina Zukowsky-Tavares has a $\mathrm{PhD}$ in Education from the Pontifical Catholic University of São Paulo and completed post-doctoral research at the University of São Paulo. She works as a professor in the Graduate Program of Health Promotion and Head of the Teacher Education program at UNASP, SP.

\section{Introduction}

Investigations and several studies which associate the use of maps to forms of representation of knowledge have been increasingly utilized by researchers in social science and in education over the last decades (Kinchin, Hay, \& Adams, 2000; Novak, 2002; Eppler, 2006; Cañas, Novak, \& Reiska, 2012).

According to the studies by Cañas, Novak, and Reiska (2012), the use of concept maps as learning and evaluation tools has turned out to be effective in facilitating learning, especially when integrated in the CmapTools software, as it allows learning in different domains of knowledge and in a variety of age ranges. Concept maps can be utilized widely in higher education, in an effort to make learning more meaningful, by overcoming the low understanding and passiveness of college students in the teaching and learning process:

The quality of conventional university teaching can be considerably improved by its use. In particular, concept mapping enables the engagement of teachers and learners in the processes of discovery. Higher education is about more than the transmission of knowledge; it entails the extension and creation of knowledge as well. (Hay, Kinchin, \& Lygo-Baker, 2008, p. 309)

Seen as a new way in the art of representing the relations between elements amidst various areas of knowledge, the cartographic language has generated an increasing fascination in the fields of epistemology and semiotics. As Novak and Cañas (2008) put it, the use of maps is about a graphical process to organize and represent knowledge, which includes concepts and relationships between concepts.

We then understand that the act of mapping, which has been used for so many years, may serve and be the object of studies and investigations associated with the construction of knowledge in both formal and non-formal educational environments. Establishing relations and hierarchically contextualizing concepts allow an individual to play a leading role in the comprehension of areas of knowledge that are put in motion (Novak \& Cañas, 2008).

\section{Concept maps and the construction of knowledge}

Concept maps were developed in the 1970's by Joseph Novak at Cornell University. The technique was designed for a research program whose objective was to follow and understand the changes in the way children see and deal with science concepts. Concept mapping then emerged as an idea to facilitate the graphic representation of the children's 
knowledge which would make it easier to identify the specific changes in their comprehension of scientific concepts (Novak, 2010). The underpinning of this work was the theory of Meaningful Learning by Ausubel (2000), who emphasized that learning takes place through the assimilation of new concepts and propositions within pre-existing concepts and propositional systems already present in the learner's mind.

According to Ausubel (2000), meaningful learning is just the first step in a wider and more inclusive process of assimilation. Based on previous knowledge, it involves the grasping of new concepts and propositions, the setting of a cognitive network which remains in constant interchange and differentiation so that the pre-existing cognitive structures act as anchorage for the assimilation of new knowledge. Thus, both new and previous pieces of knowledge are modified and new meaning is added, expanding the network and yielding new interactions.

For Novak (2010), concept maps are diagrams that allow us to hierarchically sort out superordinate and subordinate concepts of a discipline or body of knowledge, where progressive differentiation and integrative reconciliation can be achieved more effectively by "going up and down" in the conceptual structures as new pieces of information are presented.

Moreira and Mansini (2011) present concept maps as a strategy that potentially facilitate meaningful learning as they provide the conceptual structure of a subject and the role played by its conceptual systems in its development. The authors demonstrate that the concepts of a given subject are different in regard of the level of inclusiveness and generality, which allows these concepts to be presented in a hierarchical order of inclusiveness that makes learning easier as well as retaining the concepts to reach a more global view of the matter being studied. Novak and Gowin (1984) present concept mapping as an effective tool to facilitate meaningful learning. For Kinchin, Hay, and Adams (2000), the concept map can be seen as a picture of a mental model, a knowledge organization that can facilitate learning.

The quality of the work done with concept maps is also associated with the possibility of providing structured feedbacks to each individual student. Traditional evaluation methods take the opposite direction and, by doing so, they may inhibit mapping and the development of more comprehensive conceptual structures (Joseph, Conradsson, Wikmar, \& Rowe, 2017).

Within this theoretical context, this paper presents the use of concept maps as a learning strategy in Higher Education in two undergraduate health programs. According to Hay, Kinchin, and Lygo-Baker (2008), higher education is the place where knowledge construction and the use of the concept-mapping method can add significantly to the quality of university teaching.

\section{Methodology}

The concept maps utilized in this study were made individually as part of the learning activities in disciplines covering concepts of immunology in undergraduate programs of Nursing and Nutrition, in a private university in the city of São Paulo, Brazil, in 2016. Students registered in those disciplines were trained to make concept maps by using the CmapTools software developed by the Institute for Human \& Machine Cognition (IHMC). Training was provided through an adaptation of the proposal designed by De Aguiar and Correia (2013). The length of the training for the use of concept maps and its associated software was three hours. Once the training was completed and after the 
classes addressing the fundamentals of immune response were given, students prepared their concept map covering the types of immune response and then uploaded the relevant file into the Moodle platform of the disciplines so that it would be assessed by the professor in charge (Fig. 1). To make the concept maps, students were given a list of 10 concepts they should utilize together with the focal question "How does the immune system work?". It was agreed with the students that they were free to add other concepts. The list of concepts made available was: Immune response, innate, acquired, epithelial cells, NK, macrophages, humoral response, cellular response, $\mathrm{T}$ lymphocyte and $\mathrm{B}$ lymphocyte.

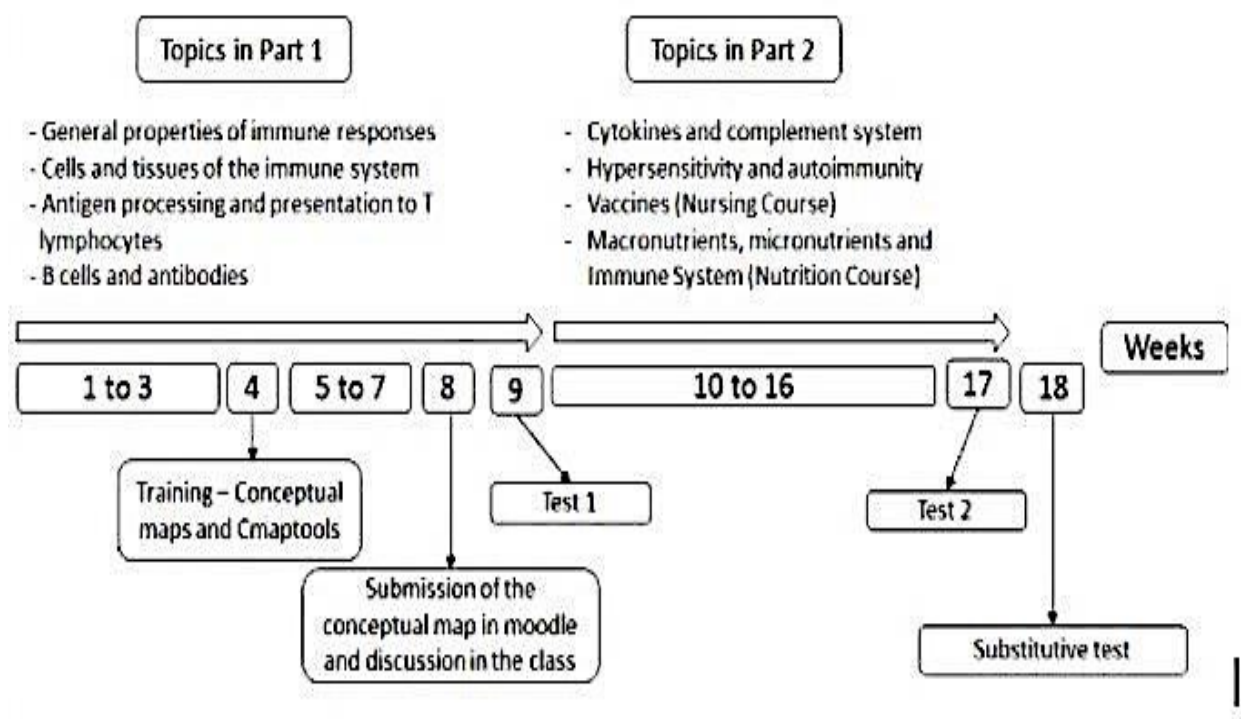

Fig. 1. Overall organization of the disciplines delivered in the courses of Nursing and Nutrition that cover subjects associated with the immune response. The training for the use of CmapTools took place in the fourth week and the concept map was collected in the eighth week of the semester.

For this research we analyzed 48 maps made by the students in compliance with the criteria adopted that would allow such map to be included in the study: first, the concept map uploaded ought to have the cmap extension and the second criterion was that each student should agree to have their concept maps utilized in the research by signing a written Free Informed Consent Form (TCLE).

The data analyzed in this study covered two fundamental elements for the making of concept maps: the propositions and the map structure. To analyze the propositions, we checked the clarity of the propositions by using the Propositional Clarity Table (PCT); propositions were sorted out as an adequate proposition (AP) or an inadequate proposition (IP). An inadequate proposition was one with no semantic clarity (NSC) and with conceptual mistakes (CM). Table 1 presents an example of PCT utilized to assess the concept maps.

For the analysis of the map morphologic structure, the concept maps were classified as spoke, chain and net (Fig. 2), according to Kinchin, Hay, and Adams (2000). The criteria used to assess the maps were defined according to the structure of each concept map and the number of hierarchy levels found in the map. In addition to the 
qualitative analysis of the morphological structure of the concept maps, we looked at the crossed connections between the concepts associated with the types of immune response: innate, acquired cellular, and acquired humoral.

\section{Table 1}

Example of a propositional clarity table used by the researchers to analyze the propositions of a concept map prepared by a student. This table presents the first 10 propositions of his/her concept map.

\begin{tabular}{crrrr}
\hline Proposition & Concept 1 & Linking Terms & Concept 2 & Analysis of Propositions* \\
\hline 1 & Acquired & Has both types & Humoral & AP \\
2 & Physical Barriers & As an example of & Skin & AP \\
3 & Helper T & Cause & Cell & IP - CM \\
4 & Lymphocytes & Destruction & AP \\
5 & Acquired & Can be & Active & AP \\
6 & NK & Promotes & Activation & AP \\
7 & Neutrophiles & Macrophages & Fagocites & IP - NSC \\
8 & Neutrophiles & Important & Inflammatory & Reaction \\
9 & Natural & Effectors & Macrophages & IPSC \\
10 & Humoral & Mediated by & Lymphocytes & AP \\
& Natural & Made up of & Biological & AP \\
\hline
\end{tabular}

Note. AP - Adequate proposition, IP - Inadequate proposition, NSC - No semantic clarity, CM - Conceptual mistakes

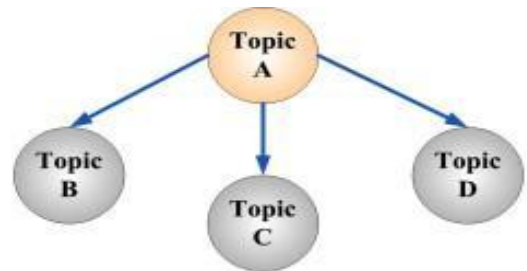

(a) The spoke structure

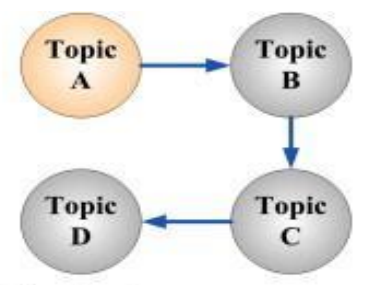

(b) The chain structure

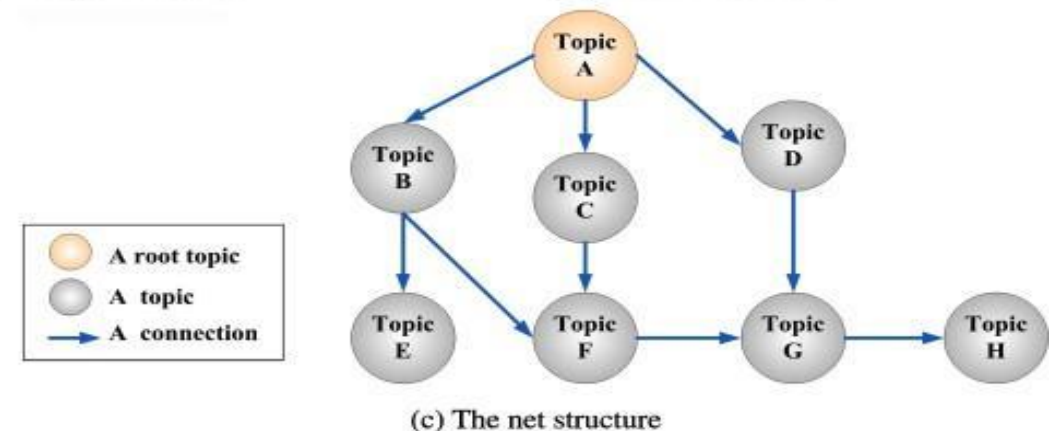

Fig. 2. Example of Cmap - Structures (http://cmapspublic3.ihmc.us/rid=1LL7CYV5X13YF2TF-5N37/cmap_morphology.jpg) 


\section{Results and discussion}

Out of the 48 concept maps we investigated, the number of propositions ranged from 12 to 62. The variation in the number of propositions in the concept maps may be a result of the way the activity was agreed upon by students and teachers. After the classes covering the fundamentals of the immune system had ended as well as the training for the use of the software, students received a list with 10 general concepts of the immune system. It was agreed with the class that maps would be collected a week before the first exam and students would be free to include new concepts when making their concept maps. Analysis allowed us to see that just two concept maps contained only the concepts presented by the teacher while the other maps had added other concepts in addition to those initially proposed. Since utilizing concept maps was a strategy for the management of learning, we observed that the concepts covered in the classes following the training were naturally included by 46 students in their maps.

Cañas, Novak, and Reiska (2012) argue that a concept map consists of both content and structure. The structure and the form through which content is presented in the map are directly correlated to the instructions supplied by the teacher for the making of concept maps. These authors point that as content and structure are freely chosen, they influence the type and quality of the concept maps made by the students. Conditions such as setting a central concept, a focal question, a list of concepts (parking lot) and the use of a restrictive list of concepts are factors that teachers must consider when evaluating the knowledge of a student when working with concept maps.

We observed that, in the process analyzed in this study, the teacher sets for the students the focal question and the list of concepts. However, we noted that the freedom to include new concepts in the maps was an aspect that contributed to a significant variation in the number of concepts and propositions.

A mass of 648 propositions were evaluated in order to determine the semantic clarity and the conceptual mistakes. Out of the total, $69.1 \%$ (448) were classified as AP and $30.9 \%(200)$ as IP. Out of the IP analyzed, $24.1 \%$ (156) did not have semantic clarity, and $6.8 \%$ (44) had conceptual errors. The percentage of $24.1 \%$ of propositions with low semantic clarity is an evidence of low proficiency in the mapping technique. Studies by Aguiar, Cicuto, and Correia (2014) present results that confirm the relevance of training activities to make students able to satisfactorily explore the mapping technique. Thus, our challenge for future works will be to give more time for training and the use of significant instructional strategies in order to empower students in the use of the mapping technique.

Out of the $6.8 \%$ of propositions that contained conceptual mistakes, we observed that such mistakes had to do mainly with the most complex topics discussed after the classes covering the fundamentals of the immune system. This is consistent with Conradty and Bogner (2008). For these authors the more difficult the subject matter, the more mistakes and thereby the more subnets and low AC (Actual Complexity) were produced in the concept map. The easier the subject, the fewer mistakes and subnets and higher AC were produced. (p.403)

All the 48 concept maps in the study were categorized as having a net structure. However, when checking cross-links established between the several types of responses by the immune system, we found that only $31,2 \%$ (15) of the concept maps, even when structured in the net form, had conceptual relations between the modes of immune response. Undergraduates made concept maps with a satisfactory structure for the 
immune responses: innate, acquired humoral, and acquired cellular; however just a few succeeded in establishing relations among such immune responses.

This investigation therefore has found that $27 \%$ (13) of the 48 concept maps were made with a high level of proficiency. These maps show no inadequate propositions, maps had a good structure, and responded to the focal issue under scrutiny.

The results achieved by this study indicate evidence of meaningful learning. According to Kinchin, Hay, and Adams (2000), students making concept maps with radial or linear structures indicate that learning is occurring in a mechanical (rote) way while those who made maps with a network structure may reveal that the learning of a given topic was achieved in meaningful way.

Buhmann and Kingsbury (2015) define five important morphological classes for the qualitative assessment of concept maps; they are: Broad, Deep, Imbalanced, Disconnected, and Interconnected. The 13 maps we have considered in this study as having a high degree of proficiency had the morphological characteristics of Interconnected concept maps. These maps are distinguished by the high level of interconnections between the concepts, because they are large and well-structured maps, and they have a network of concepts that is well connected.

It was seen that the mappers were able to identify that the immune responses are subdivided into 'innate' and 'acquired'. They associated the major components of each immune response and presented propositions that clearly show the construction of the key concepts regarding the immune response. However, as the concepts became more and more specific, the propositions with conceptual errors came up as, for example, in the proposition "HELPER T LYMPHOCYTES cause CELL DESTRUCTION".

The conceptual mistakes found in the concept maps are significant for the teaching praxis, as identifying conceptual mistakes in the students' maps provides the opportunity to reorganize teaching strategies in each classroom. The use of the mapping technique is a crucial factor in the learning process and it is repeatedly described in the literature as a tool that can support and enhance student's learning in science classrooms (Kinchin, 2001). The distance between the teacher's and the students' knowledge can be revealed by comparing concept maps. However, the use of the mapping technique is also a key factor to increase the pedagogic resonance between teachers and students. For Trigwell and Shale (2004) pedagogic resonance is the bridge between teaching knowledge and the student's learning that results from that knowledge (p. 532). Since mapping allows a teacher to identify problems associated with the construction of the student's specific knowledge, he or she can devise strategies to mitigate these deficiencies in the learner's process of constructing knowledge (Kinchin, Lygo-Baker, \& Hay, 2008). Students must see conceptual mistake as a new learning opportunity. According to Novak (2002) using the conceptual errors found in the maps made by the students contributes to guide the next steps of learning. We will now present some of the concept maps made by the students.

In Fig. 3, we note that the map had utilized only the concepts supplied by the teacher and had developed a structure for the map that that took the form of a network with four hierarchical levels regarding the topic covered. No conceptual mistakes were detected and all propositions displayed in the diagram are semantically clear. It is possible to see that the map-maker was able to establish relationships between the subconcepts of innate and acquired immune response. In the map, the student identifies the components of the immune response in the proposition "INNATE is made up by MACROPHAGES" and he/she also associates the innate immune response with the 
acquired immune response of the cellular type when setting the proposition "MACROPHAGES show antigens for T LYMPHOCYTE". In the teacher's assessment, these concept maps did not bring the concepts that had been covered in the classes following the training. The concepts and the propositions presented were limited to the topics associated with the fundamentals of the immune system.

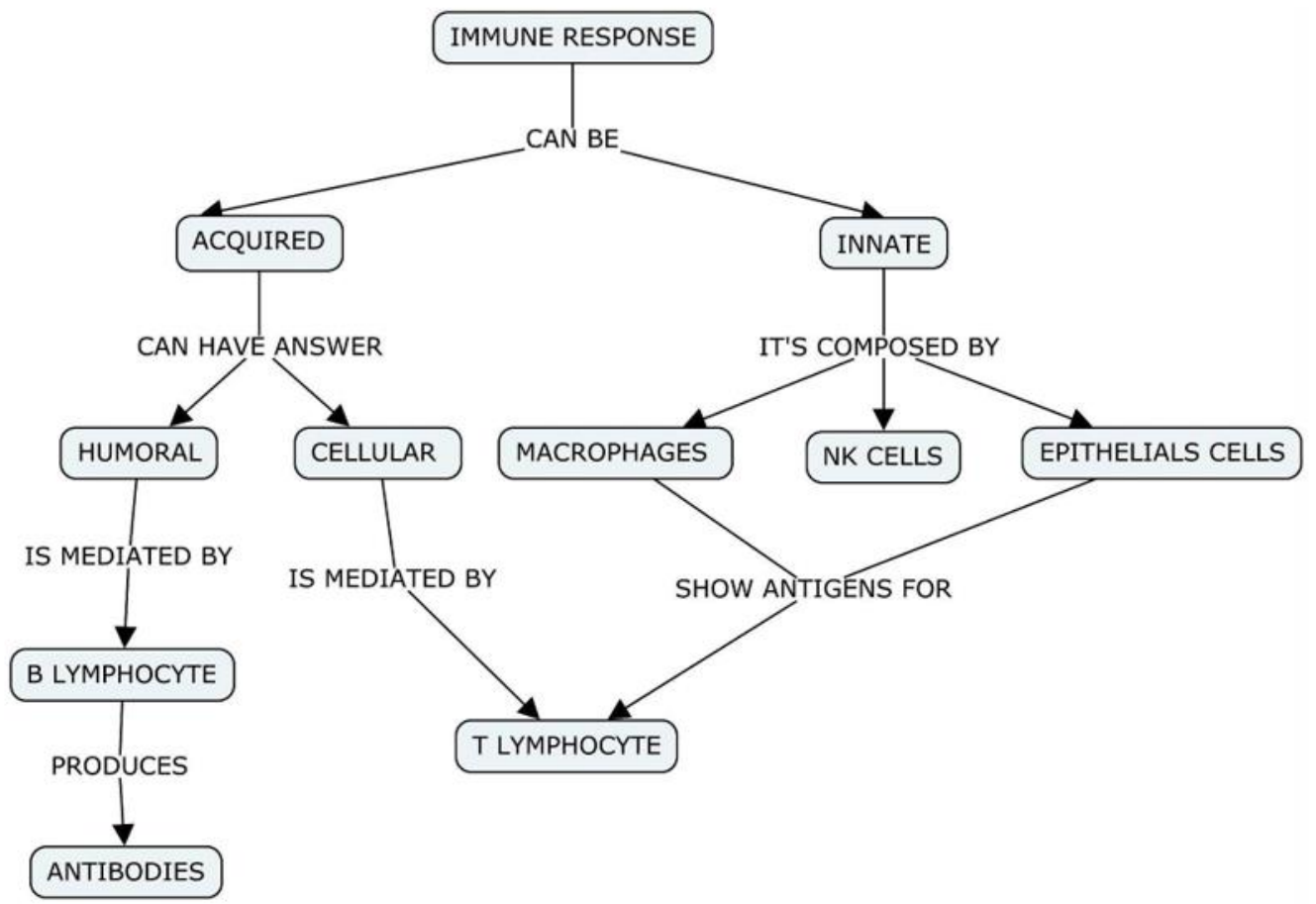

Fig. 3. Concept map made by an undergraduate containing only the concepts supplied by the professor; concepts show satisfactory proficiency

In the context of the teaching and learning activity proposed by the teacher, he/she assessed the concept maps and handed them back to the students. Moreover, some concept maps were selected and presented to the whole class in order to have conceptual mistakes identified, if any. Fig. 4 is an example of a concept map containing concept errors and inadequate propositions.

An example of a concept map with several interconnections is presented in Fig. 5. The map maker utilized concepts supplied by the professor, added other concepts required to make the map, organized the map with colors according to the type of immune response, and established conceptual relations among the different types of immune response. In addition, the concept map reveals that the student was capable of establishing propositions by utilizing concepts of different hierarchy levels, which allowed the development of a coherent network structure that was well designed.

In general, the analyses we have done clearly showed that the concept maps made by the students included concepts that were representative of the content covered in the program. Such content was sorted out and correlated in a hierarchical manner, from broader aspects to the small details. We believe that the use of the tool was a facilitator in supporting and increasing the students' learning. 


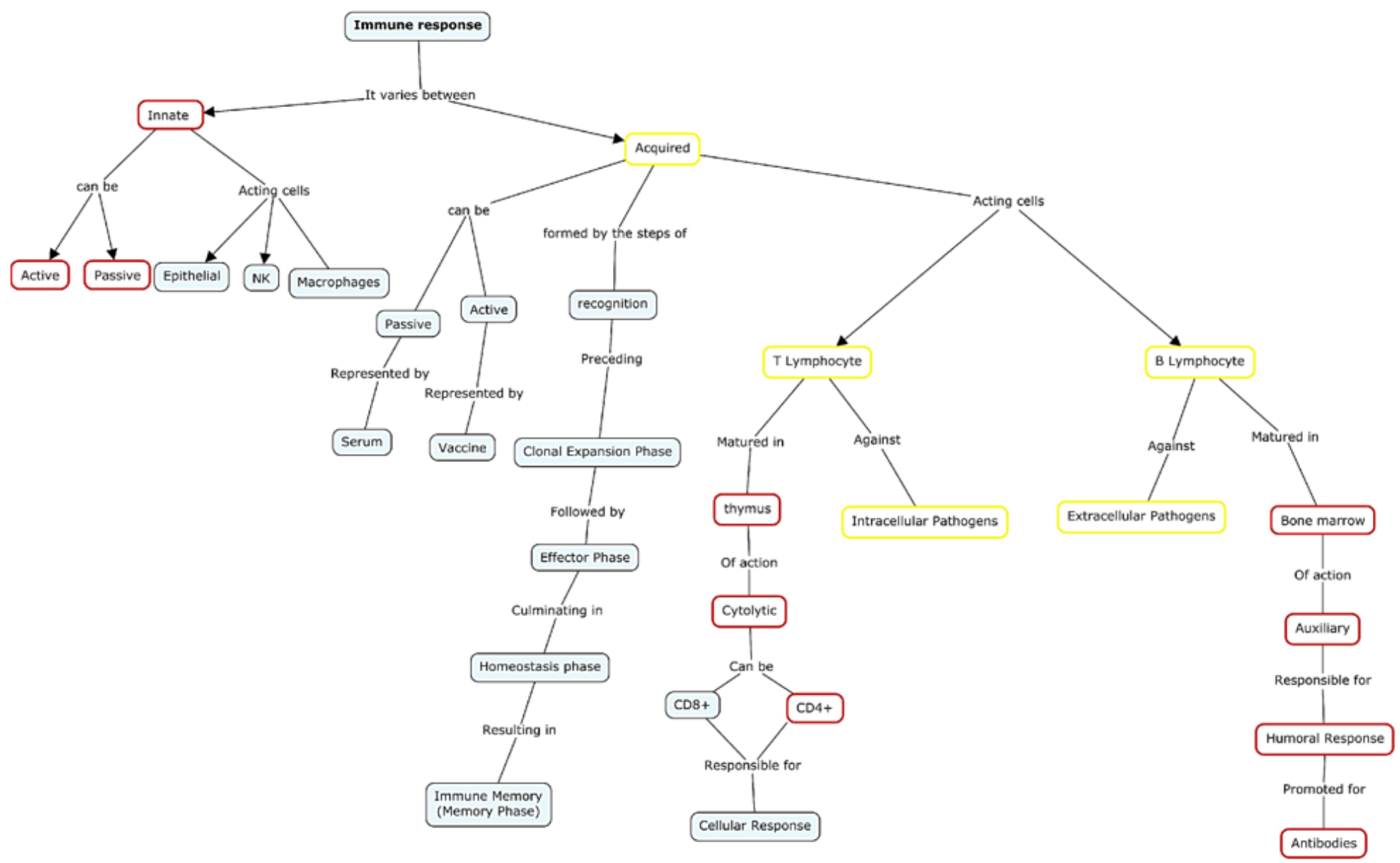

Fig. 4. Example of a concept map made by an undergraduate student containing conceptual mistakes and propositions with low semantic clarity

\section{Conclusion}

The use of concept maps as part of a learning strategy in undergraduate courses in the field of Health, as presented in this study, yielded motivation and involvement of the students towards the activity of learning the functioning of the immune system. Through this experience we realized the importance of concept mapping as an effective tool to facilitate learning, especially when integrated to the software Cmap Tools, as proposed by Cañas, Novak, and Reiska (2012), as a learning method that may significantly add to the quality of higher education teaching, as argued by Hay, Kinchin, and Lygo-Baker (2008).

For us, the successful outcome of this work was to make undergraduates learn concepts associated with the basis of the immunological responses, in a meaningful way (Ausubel, 2000). We could see that this has really happened as the concept maps we 
analyzed had $69 \%$ of AP and 100 percent of network structure. Another matter that should be highlighted was how easily some difficulties were overcome by the undergraduates in the making of their maps. We observed that only $31.2 \%$ (15) of the concept maps, even when structured in the network form, presented conceptual relations between the types of immune response, and out of them, $27 \%$ of the concept maps were made with several interconnections between the concepts. It must be emphasized that these maps were the ones which displayed relations in a more thorough way regarding the innate, humoral acquired, and cellular acquired immune responses. Also, they established relations between these immune responses. We consider that this low percentage results from the assimilation by undergraduates of the mapping processes. This makes us face a challenge while it also reveals limits and weaknesses that need more careful attention in our next studies: how can the students' skill for making concept maps be improved? Can Moodle as a learning environment be utilized as a link for online communication and reorientation in the process of making and revising the concept maps?

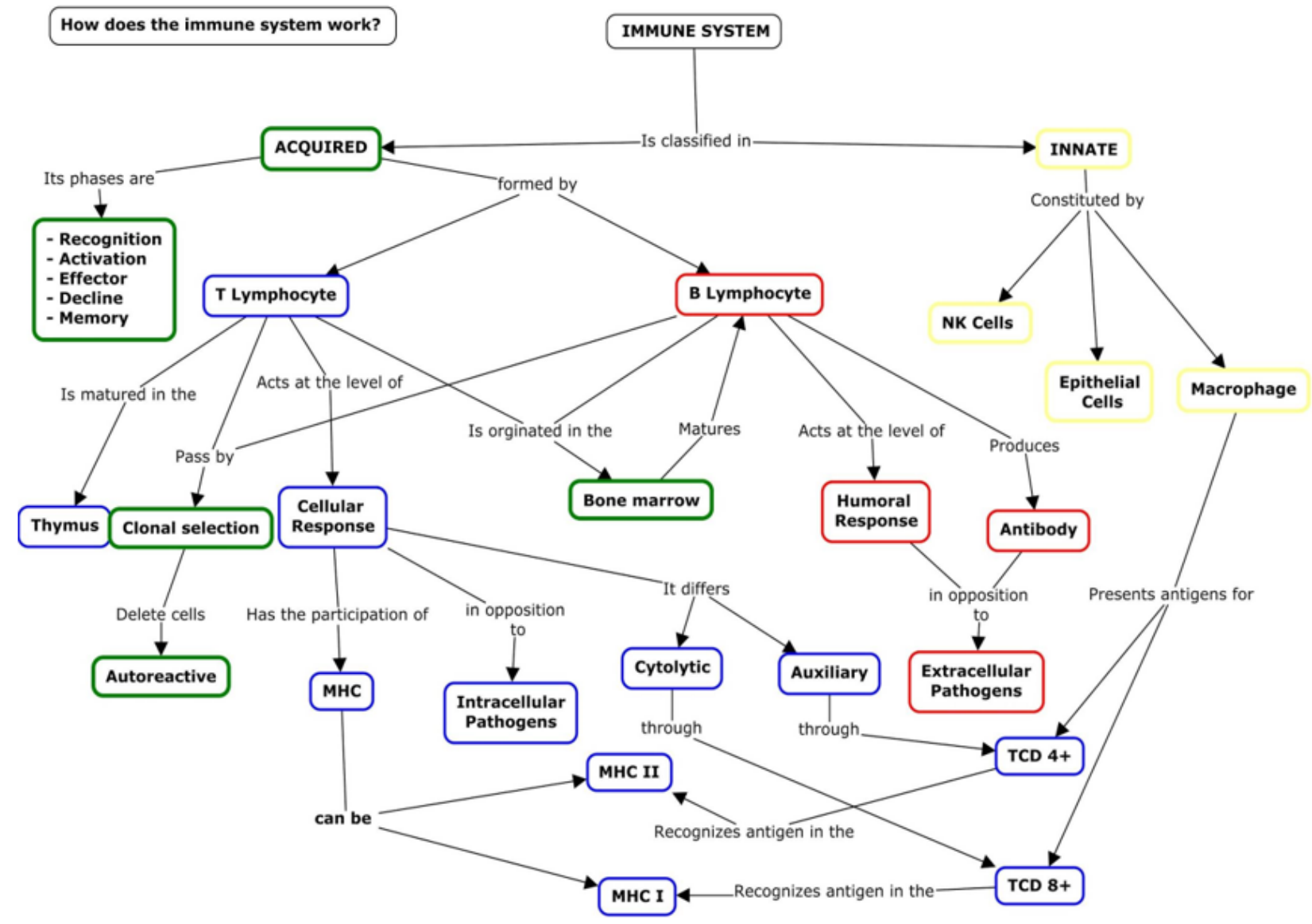

Fig. 5. Concept map prepared by an undergraduate student covering immunology topics. The student establishes several interconnections between the concepts and uses colors for

the concepts associated with the innate immune response , the humoral acquired immune response $\square$, the cellular acquired immune response $\square$, and for the concepts shared by the cellular and the acquired immune responses 
Thus, in the light of the results brought by this article, we may conclude that there is still a long road to follow in the development of the mapping strategy. We suggest an in-depth approach to the issues related to the pedagogical process of constructing, organizing and representing knowledge and the planning of actions which will allow students to utilize concept maps in the other disciplines of the undergraduate health courses. It must be emphasized that mapping concepts in higher education encourages participation and allows both teachers and students to be involved in processes of learning (Hay, Kinchin, \& Lygo-Baker, 2008). That said, we understand that adopting the mapping strategy in a systematic manner will help undergraduates to establish the several connections required in the learning process. The continuous use of the strategy may also contribute to the develop the skills that undergraduate students need to manage their learning in a critical and autonomous fashion, integrated to other fields of knowledge that they are constructing.

\section{References}

Aguiar, J. G., Cicuto, C. A. T., \& Correia, P. R. M. (2014). How can we prepare effective concept maps? Training procedures and assessment tools to evaluate mapper' proficiency. Journal of Science Education, 15(1), 14-19.

Ausubel, D. P. (2000). The acquisition and retention of knowledge: A cognitive view. Netherlands: Springer.

Buhmann, S. Y., \& Kingsbury, M. (2015). A standardised, holistic framework for concept-map analysis combining topological attributes and global morphologies. Knowledge Management \& E-Learning, 7(1), 20-35.

Cañas, A. J., Novak, J. D., \& Reiska, P. (2012). Freedom vs. restriction of content and structure during concept mapping-Possibilities and limitations for construction and assessment. In Proceedings of the 5th International Conference on Concept Mapping (Vol. 2, pp. 247-257). Malta: Veritas Press.

Conradty, C., \& Bogner, F. X. (2008). Faults in concept mapping: A matter of technique or subject? In Proceedings of the 3rd International Conference on Concept Mapping (Vol. 2, pp. 399-405). Põltsamaa: OÜ Vali Press.

De Aguiar, J. G., \& Correia, P. R. M. (2013). Como fazer bons mapas conceituais? estabelecendo parâmetros de referência e propondo atividades de treinamento. Revista Brasileira de Pesquisa em Educação Ciências, 13(2), 141-157.

Eppler, M. J. (2006). A comparison between concept maps, mind maps, conceptual diagrams, and visual metaphors as complementary tools for knowledge construction and sharing. Information Visualization, 5(3), 202-210.

Hay, D., Kinchin, I., \& Lygo-Baker, S. (2008). Making learning visible: The role of concept mapping in higher education. Studies in Higher Education, 33(3), 295-311.

Joseph, C., Conradsson, D., Wikmar, L. N., \& Rowe, M. (2017). Structured feedback on students' concept maps: The proverbial path to learning? BMC Medical Education, 17: 90.

Kinchin, I. M. (2001). If concept mapping is so helpful to learning biology, why aren't we all doing it? International Journal of Science Education. 23(12), 1257-1269.

Kinchin, I. M., Hay, D. B., \& Adams, A. (2000). How a qualitative approach to concept map analysis can be used to aid learning by illustrating patterns of conceptual development. Educational Research, 42(1), 43-57.

Kinchin, I. M., Lygo-Baker, S., \& Hay, D. B. (2008). Universities as centres of nonlearning. Studies in Higher Education, 33(1), 89-103.

Moreira, M. A., \& Masini, E. F. S. (2011). Aprendizagem significativa - A teoria de David Ausubel (2nd ed), São Paulo: Centauro Editora. 
Novak, J. D. (2002). Meaningful learning: The essential factor for conceptual change in limited or inappropriate propositional hierarchies leading to empowerment of learners. Science Education, 86(4), 548-571.

Novak, J, D. (2010). Learning, creating, and using knowledge: Concept maps as facilitative tools in schools and corporations. Journal of e-Learning and Knowledge Society, 6(3), 21-30. Retrieved from http://rodallrich.com/advphysiology/ausubel.pdf

Novak, J. D., \& Cañas, A. J. (2008). The theory underlying concept maps and how to construct and use them. Pensacola, FL: Institute for Human and Machine Cognition. Retrieved from http://cmap.ihmc.us/docs/theory-of-concept-maps

Novak, J. D., \& Gowin, D. B. (1984). Learning how to learn. Cambridge: Cambridge University Press.

Trigwell, K., \& Shale, S. (2004). Student learning and the scholarship of university teaching. Studies in Higher Education, 29(4), 523-536. 